\section{Indian Society of Neuroanaesthesiology and Critical Care 2016 Conference Report}

\section{Sonia Bansal}

The $17^{\text {th }}$ Annual Conference of Indian Society of Neuroanaesthesiology and Critical Care (ISNACC 2016) was organised at the National Institute of Mental Health and Neurosciences (NIMHANS) convention centre, Bengaluru, India, from 05 to 07 February 2016. The organising secretary, Dr. H. K. Venkatesh conducted this conference in collaboration with Department of Neuroanaesthesia, NIMHANS, Bengaluru.

An increase in the volume and complexity of neurosurgical procedures has led to rapid parallel advancements in the field to Neurocritical care. Hence, the theme for this year's conference was 'Neuro Critical Care - Neuronal Preservation to Protection'. Renowned international faculty and distinguished national faculty deliberated on the progress in the field of Neuroanaesthesia and Neurocritical care. The conference was attended by more than 400 delegates from worldwide.

A1-day training course on 'Emergency Neurological Life Support' was successfully conducted by the faculty from Neurocritical Care Society of US, as a pre-conference workshop on 04 February 2016. We received an overwhelming response and more than 125 delegates enrolled for the course.

The $1^{\text {st }}$ day of the conference began with a session on 'Biomarkers in Neurocritical care' and 'Challenges in paediatric neurocritical care' being delivered by eminent speakers, Dr. JoseSuarez and Dr. G. S. Umamaheswara Rao. This was followed by a symposium on Evoked Potentials covering Somatosensory, Brainstem auditory and Motor evoked potentials being delivered by Dr. Georgene

Department of Neuroanesthesia, National Institute of Mental Health and Neurosciences, Bengaluru, Karnataka, India

Address for correspondence:

Dr. Sonia Bansal, Department of Neuroanesthesia,

National Institute of Mental Health and Neurosciences,

Bengaluru - 560 029, Karnataka, India.

E-mail: rashibpgi@yahoo.co.in
Singh, Dr. Nishanth Sampath and Dr. Matthew Chan, respectively. There were talks on fundamental topics such as 'Ischaemic post-conditioning following cerebral ischaemia' and 'Pathophysiologic mechanisms and experimental therapies in cerebral oedema' by Dr. Sanjay Banakal and Dr. Hemant Bhagat. Focussed neurocritical care topics such as 'Management of Acute ischaemic stroke', Nutrition in neurointensive care and outcomes' and 'Non-invasive methods of measuring ICP' were elaborately presented by Dr. Jose Suarez, Dr. Prasanna Bidkar and Dr. Gentle Shrestha. Issues pertinent to the practice of Neuroanaesthesia such as 'Pregnancy and neurological patients', 'Management of patients with Pituitary tumours', 'Anaesthetic implications of Intra-operative MRI' and 'Anaesthesia for Interventional Neuroradiological Procedures' were comprehensively presented by eminent faculties, Dr. V. Ponnaiah, Dr. Mary Abraham, Dr. Kavita Sandhu and Dr. Anil Parakh.

In the evening, the inaugural function of the meeting was held at NIMHANS convention centre. During the function, certificates were distributed to the Post-doctoral Fellowship students of Neuroanaesthesia, trained under the academic programme of the society at various accredited hospitals across the country. A mobile-based app for survey of management of Head Injured patients was also released by the President ISNACC during the inaugural ceremony. This was followed by Professor Gode Oration delivered by Dr. Rajiv Chawla on 'Safety in Neuroanaesthesia and Neurocritical Care'.

The scientific meeting on the $2^{\text {nd }}$ day started with session on 'Beneficial evidence of Neurocritical Care versus General ICU' by Dr. Ian Tweedie, 'Improving outcomes in patients undergoing spinal surgery' by Dr. Padmaja Durga and 'Current role of Hyperoxia in Neurological patients' by Dr. Parthasarathi Goswami. This session was followed by symposium on 'Brain Injury and Organ dysfunction' comprising injury to brain with interactions on cardiac, lung and kidney dysfunction. The areas were addressed by Dr. Manikandan, Dr. Michel Torbey and Dr. Dilip Kulkarni, respectively. Pre-lunch, Dr. Malathi Memorial Oration and Dr. Hariwir Singh Orations were delivered by Dr. Sergio Bergese and Dr. Ramani Ramachandran, respectively. They spoke on Fragile Brains, 'The Brain of the Elderly' and 'Functional Connectivity and Large Scale Neuroscience', respectively. Post-lunch, there was a panel discussion moderated by Dr. Hemanshu Prabhakar with four panellists (Dr. Sergio Bergese, Dr. Ian Tweedie, Dr. H. H. Dash and Dr. Joseph Monteiro), on how to practically manage certain challenging situations frequently encountered in the practice of 
Neuroanaesthesia and Neurocritical Care. This was followed by another symposium on 'Neuromonitoring'. The monitoring included was 'Current status of Near Infrared Spectroscopy', 'Cerebral sonology' and 'Monitoring metabolic parameters of the ischaemic brain' and the respective speakers were Dr. Gyaninder Pal Singh, Dr. B. Lokesh and Dr. Girija Rath. The scientific programme of the day concluded with talks on 'Leadership skills in anaesthesia', 'Perioperative fluid management in neurosurgical patients' and 'Management of pain in neurocritical care unit' by Dr. Arpan Guha, Dr. Zulfiqar Ali and Dr. Raghavendra Pai. This was followed by General Body Meeting.

The last day of the meeting commenced with Society for Neuroscience in Anesthesiology and Critical Care (SNACC) panel presentations on 'Neuroprotection in Neurocritical care', 'Sedation practices in neurocritical

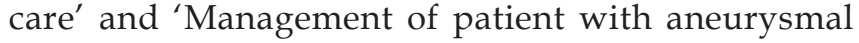
subarachnoid haemorrhage in neurocritical care unit'. The talks were delivered by members of SNACC panel, Dr. Ines Koerner and Dr. Abhijit Lele. A brainstorming session comprising topics relevant to recent advances in the practice of neuroanaesthesia, 'Haemodynamic monitoring and neurological outcomes', 'Pros and cons of using neuromuscular blockers in neurological surgeries' and 'Low flow anaesthesia in neurosurgical practice' were delivered by Dr. Gokul Das, Dr. V. Smita and Dr. Murali Thondebhavi. Pre-lunch topics, especially significant to neurocritical care, i.e. 'In neurocritical care', 'Genomics relevant to neuroanaesthesiologist', 'Choosing the correct antibiotic in hospital-acquired infections' and 'Management of organ donor following brain death' by Dr. Smita Sharma, Dr. Vidya Chidambaran, Dr. Subramanian Swaminathan and Dr. T. R. Chandrashekar were presented.

There were a total of 54 poster presentations on all the days of the conference. The conference concluded with six award paper presentations judged by Dr. Bala Bhaskar, Dr. Ramani Ramachandran and Dr. Dilip Kulkarni. The judges appreciated the speakers for their presentations. This was followed by valedictory function during which prizes were given to six best poster presentations of the conference and award paper presentations. The first prize among award paper presentations was received by Dr. Kaushic Theerth from NIMHANS, Bengaluru, for the paper titled, 'Cerebral oxygenation during electroconvulsive therapy'.

The organising secretary thanked the organising team and on behalf of the organising team, he also thanked all the delegates for their active participation in the meeting. The conference was well attended and much appreciated by one and all.

\section{Financial support and sponsorship}

Nil.

\section{Conflicts of interest}

There are no conflicts of interest.

This is an open access article distributed under the terms of the Creative Commons Attribution-NonCommercial-ShareAlike 3.0 License, which allows others to remix, tweak, and build upon the work non-commercially, as long as the author is credited and the new creations are licensed under the identical terms.

\begin{tabular}{|l|l|}
\hline \multicolumn{2}{|c|}{ Access this article online } \\
\hline Quick Response Code: & Website: \\
\hline & www.jnaccjournal.org \\
\cline { 2 - 2 } & \\
\hline
\end{tabular}

How to cite this article: Bansal S. Indian society of neuroanaesthesiology and critical care 2016 conference report. J Neuroanaesthesiol Crit Care 2016;3:162-3. 